\title{
Performance Evaluation of STRATUS CS200 for Cardiac Markers
}

\author{
Yong-Wha Lee and \\ Jeong Gwon Kim \\ Department of Laboratory \\ Medicine and Genetics, \\ Soonchunhyang University \\ Bucheon Hospital, \\ Soonchunhyang University \\ College of Medicine, \\ Bucheon, Korea
}

Corresponding author:
Yong-Wha Lee
Department of Laboratory
Medicine and Genetics,
Soonchunhyang University
Bucheon Hospital,
Soonchunhyang University
College of Medicine, 170 Jomaru-
ro, Wonmi-gu, Bucheon 14584,
Korea
Tel: +82-32-621-5943
Fax: +82-32-621-5944
E-mail: lywmd@schmc.ac.kr
pISSN: 2384-2458
eISSN: 2288-7261

The STRATUS CS200 (Siemens Healthcare Diagnostics Inc., USA) has recently been developed as an on-site diagnostic instrument for assaying several kinds of cardiac markers within a short duration. The precision, linearity, comparison, limit of quantification, and turnaround time (TAT) were evaluated for troponin I, creatine kinase-MB (CK-MB), $\mathrm{N}$-terminal pro-brain natriuretic peptide (NT-proBNP), and myoglobin assays according to guidelines provided by the Clinical and Laboratory Standards Institute. The total coefficients of variation of the four items were between $1.90 \%$ and $4.25 \%$. All markers showed a linearity that was $\geq 0.99$, and the values were within the manufacturer's range. All items showed a close correlation with E170 (Roche Diagnostics, Germany). The limits of quantification for troponin I, CK-MB, myoglobin, and NT-proBNP were $0.03 \mathrm{ng} / \mathrm{mL}, 0.3 \mathrm{ng} / \mathrm{mL}, 1 \mathrm{ng} / \mathrm{mL}$, and $15 \mathrm{pg} / \mathrm{mL}$, respectively. The TAT was 14 minutes. The performance of the STRATUS CS200 for assaying cardiac markers was highly satisfactory in terms of the precision, linearity, limit of quantification, and TAT, and it showed a good correlation with the comparative method. (J Lab Med Qual Assur 2017;39:181-184)

Key Words: Cardiac marker, Evaluation, STRATUS CS200
급성심근경색은 초기 선별에 따른 즉각적인 처치가 매우 중 요하다. 이를 위해 현장에서 간편하고 신속하게 선별할 수 있 는 검사가 필요하다. 최근 고체상 방사 분할 면역측정법 원 리가 적용된 현장검사기기로 자체 원심분리기능을 갖추고 다양한 심표지자검사를 수행할 수 있는 STRATUS CS200 (Siemens Healthcare Diagnostics Inc., Newark, DE, USA) 이 개발되었다.

본 연구에서는 Clinical and Laboratory Standards Institute (CLSI)에 제시된 평가지침에 따라 CS20과 전용 카 트리지를 이용하여 측정 가능한 troponin I, creatine kinase$\mathrm{MB}$ (CK-MB), N-terminal pro-brain natriuretic peptide (NT-proBNP)와 myoglobin 등 총 4종목에 대하여 정밀도, 직 선성, 상관성 및 정량한계를 평가하고자 하였고, 검사소요시간 을 측정하였다.
심표지자검사가 의뢰된 환자의 리튬 헤파린 용기에 수집된 혈액으로부터 분리된 혈장 검체와 내부정도관리용 물질을 이 용하여 평가하였다. 4종목에 대해 두 농도의 정도관리용 물질 을 이용하여 CLSI 기준에 맞추어 5일간 오전, 오후에 반복검 사 수행 후 총 변이계수를 구하였고, 고농도와 저농도의 물질 을 이용하여 5 가지 농도로 희석 후 반복 측정하여 직선성을 보 이는 구간을 검증하였으며, 종목별로 40개 이상의 다양한 값 을 보이는 혈장 검체를 이용하여 중앙검사실의 E170 (Roche Diagnostics, Mannheim, Germany)과의 상관성을 PassingBablok 회귀식을 이용하여 평가하였고 제조사에서 제시한 정 량한계에 근접한 농도를 갖는 물질을 이용하여 변이계수를 이 용한 정량한계를 검증하였다[1-3].

각각의 평가에 대한 통계는 Microsoft Office Excel 2007 (Microsoft Co., Redmond, WA, USA) 프로그램을 이용하여 


\section{Journal of LABORATORY MEDICINE and QUALITY ASSURANCE \\ Yong-Wha Lee et al • STRATUS CS200 for Cardiac Markers}

Table 1. Precision of troponin I, CK-MB, myoglobin, and NT-proBNP detection was determined using high- and low-level quality control materials (BIO-RAD Liquichek Cardiac Markers Plus Controls 1 and 3) in the CS200 system

\begin{tabular}{|c|c|c|c|c|}
\hline Items (units) & Level & Mean \pm standard deviation & Coefficient of variation (\%) & Desirable precision $(\%)^{*}$ \\
\hline \multirow[t]{2}{*}{ Troponin I (ng/mL) } & High & $5.39 \pm 0.12$ & 2.32 & 7.03 \\
\hline & Low & $0.45 \pm 0.02$ & 4.25 & \\
\hline \multirow[t]{2}{*}{ CK-MB (ng/mL) } & High & $94.06 \pm 1.93$ & 2.05 & 9.20 \\
\hline & Low & $3.09 \pm 0.11$ & 3.47 & \\
\hline \multirow[t]{2}{*}{ Myoglobin (ng/mL) } & High & $253.55 \pm 4.90$ & 1.90 & 7.00 \\
\hline & Low & $35.50 \pm 0.69$ & 1.94 & \\
\hline \multirow[t]{2}{*}{ NT-proBNP (pg/mL) } & High & $7,261.50 \pm 174.76$ & 2.41 & 5.00 \\
\hline & Low & $171.04 \pm 4.30$ & 2.51 & \\
\hline
\end{tabular}

Abbreviations: CK-MB, creatine kinase-MB; NT-proBNP, N terminal pro brain natriuretic peptide.

${ }^{*}$ Based on the Westgard QC (http://www.westgard.com/biodatabase1.htm).

Table 2. Linearity of troponin I, CK-MB, myoglobin, and NT-proBNP assays, performed using CS200

\begin{tabular}{lcccc}
\hline Items & Units & Linearity range & $R^{2}$ & Best fit \\
\hline Troponin I & $\mathrm{ng} / \mathrm{mL}$ & $0.03-50.00$ & 0.9990 & Linear fit \\
CK-MB & $\mathrm{ng} / \mathrm{mL}$ & $0.3-150.0$ & 0.9980 & 3rd order polynomial \\
Myoglobin & $\mathrm{ng} / \mathrm{mL}$ & $1.0-900.0$ & 0.9980 & 2nd order polynomial \\
NT-proBNP & $\mathrm{pg} / \mathrm{mL}$ & $15-20,000$ & 0.9940 & 3rd order polynomial \\
\hline
\end{tabular}

Abbreviations: CK-MB, creatine kinase-MB; NT-proBNP, N terminal pro brain natriuretic peptide; $R^{2}$, coefficient of determinations.

A

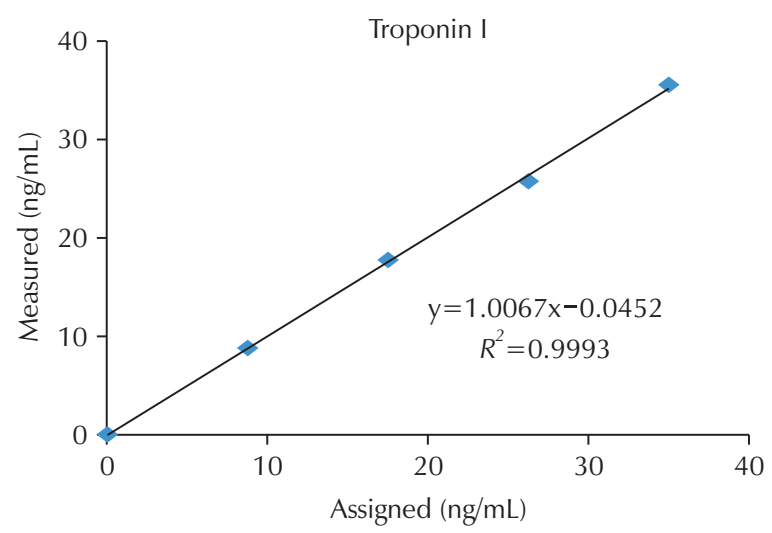

C

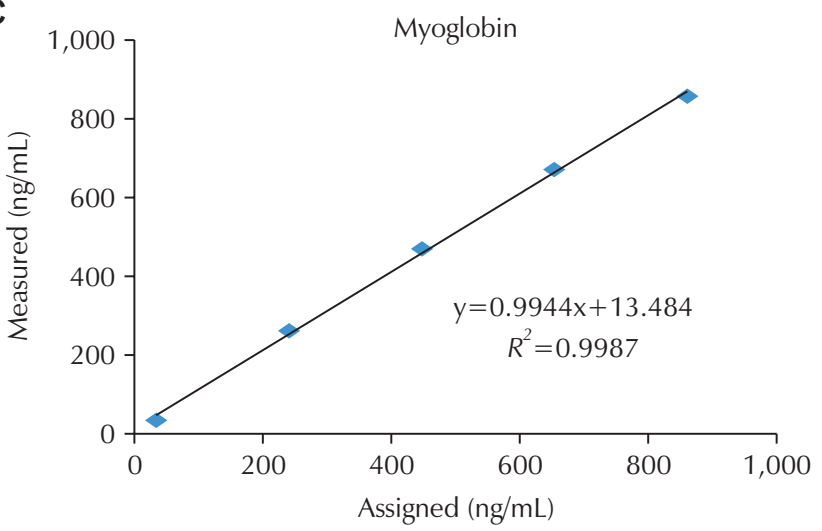

B

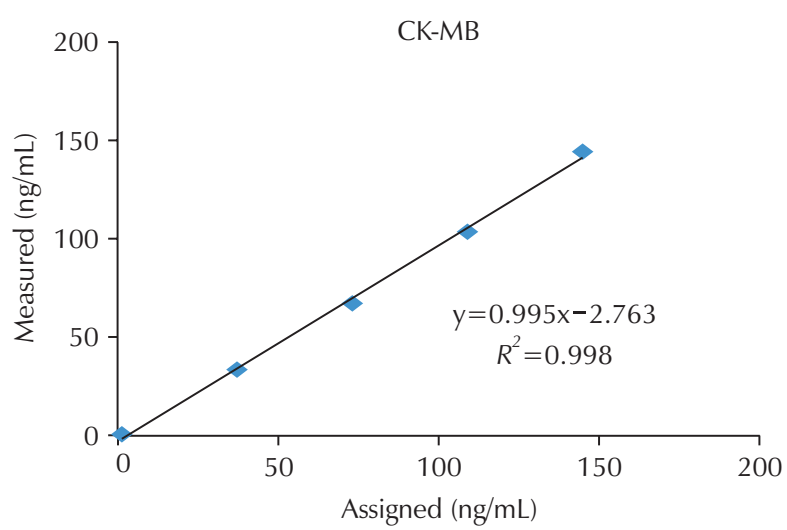

D

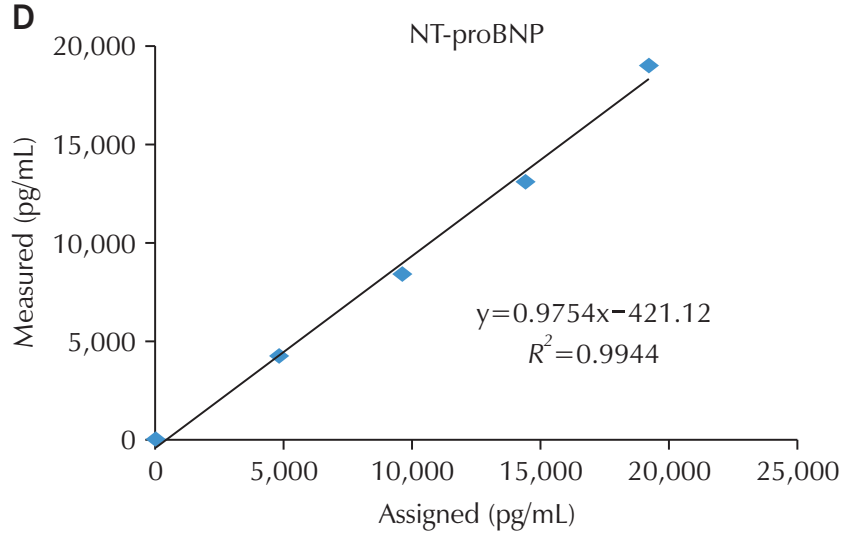

Fig. 1. Linearity analyses using CS200. Troponin I (A), CK-MB (B), myoglobin (C), and NT-proBNP (D). 


\section{Journal of LABORATORY MEDICINE and QUALITY ASSURANCE \\ Yong-Wha Lee et al • STRATUS CS200 for Cardiac Markers}

A

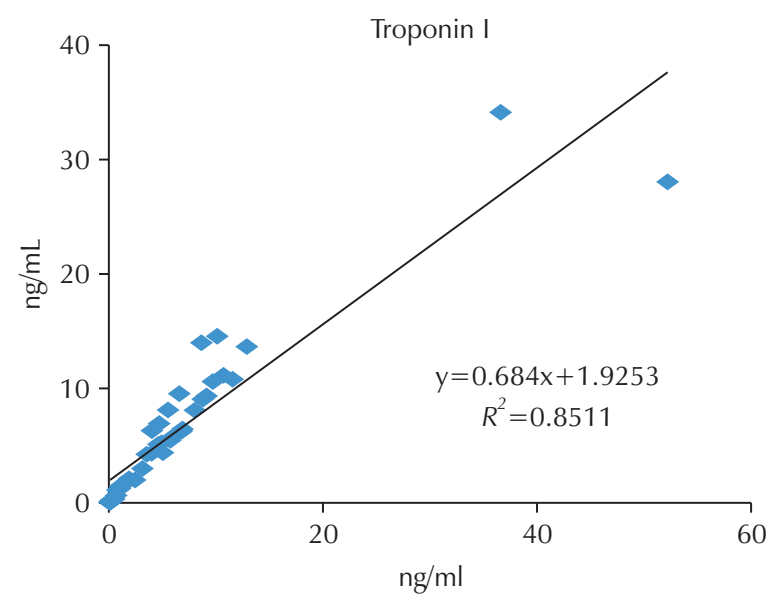

C

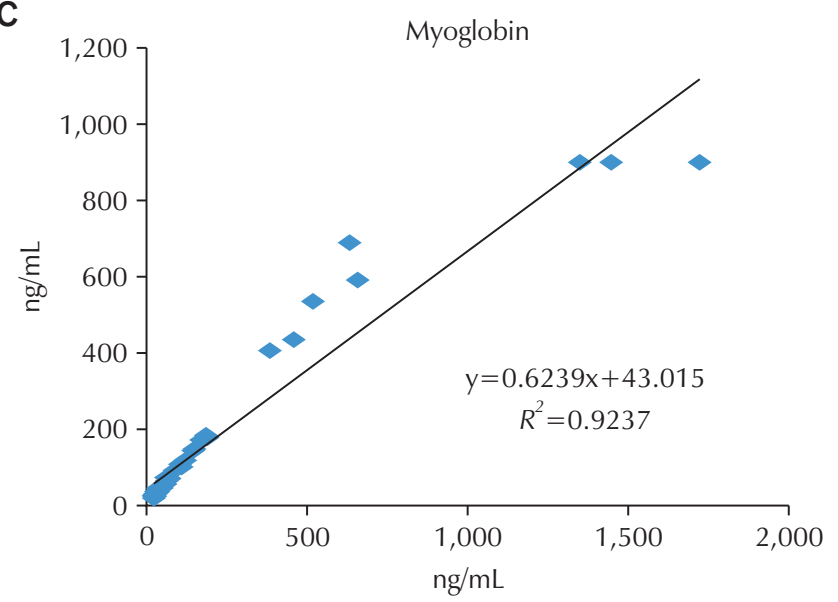

B

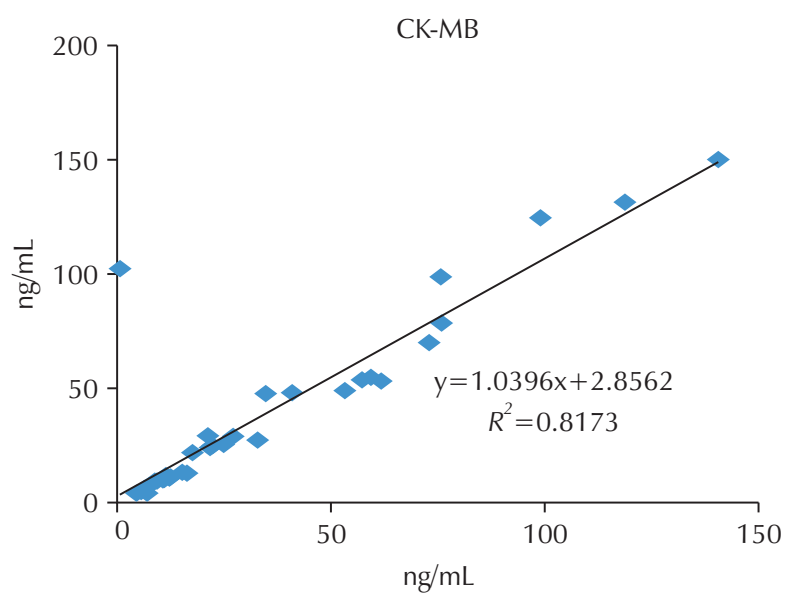

D

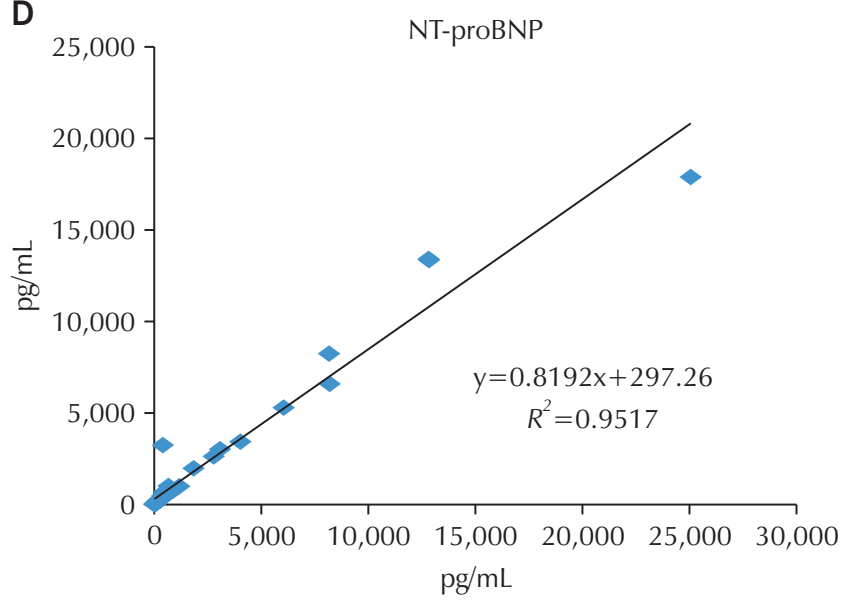

Fig. 2. Correlation of troponin I, CK-MB, myoglobin, and NT-proBNP concentrations between CS200 (Y-axis) and E170 (X-axis). Passing and Bablok regression scatter plot for troponin I (A), CK-MB (B), myoglobin (C), and NT-proBNP (D).

\section{분석하였다.}

4종목의 총 변이계수는 고농도물질은 $1.90 \%-2.41 \%$ 의 값 을 보였고, 저농도물질은 $1.94 \%-4.25 \%$ 의 값을 보였다(Table 1). 직선성 평가에서 4종목 모두 제조사 제시범위 내에서 결정 계수가 0.99 이상이었고, troponin I는 직선식이 합당하였던 반면, myoglobin은 2차 다항회귀곡선이 합당하였고, $\mathrm{CK}-\mathrm{MB}$ 와 NT-proBNP는 3차 다항회귀곡선이 가장 적합하였다 (Table 2, Fig. 1). E170과의 상관성 평가에서 4종목 모두 상 관계수가 0.9 이상으로 나타나 밀접한 상관성을 보였다(Fig. 2). 제조사에서 제시한 정량한계치는 troponin I, CK-MB, myoglobin과 NT-proBNP가 각각 $0.03 \mathrm{ng} / \mathrm{mL}, 0.3 \mathrm{ng} / \mathrm{mL}$, $1 \mathrm{ng} / \mathrm{mL}$ 와 $15 \mathrm{pg} / \mathrm{mL}$ 였으며 이에 해당하는 농도를 갖는 물질 에 대한 10 회 반복 측정결과 변이계수는 각각 $15.4 \%, 16.1 \%$, $23.4 \%$ 와 $8.1 \%$ 로 분석되었다. 검사소요시간은 한 결과를 얻 기까지는 14 분이 소요되었고 네 개의 결과를 얻기까지는 26 분
이 소요되었다.

$\mathrm{CS} 200$ 을 이용한 심표지자검사는 정밀도와 직선성에 있어 서 매우 만족할 만한 성능을 보였고, 중앙검사실 기기와도 좋 은 상관성을 보였을 뿐만 아니라 낮은 농도에서도 매우 높은 정밀도를 보였다. CS200을 이용한 심표지자검사는 심근경색 이 의심되는 환자의 신속하고 정확한 선별이 가능한 유용한 검 사법으로 평가되었다.

\section{감사의 글}

본 연구에 지원을 아끼지 않은 지멘스헬스케어(주)에 깊은 감 사를 드린다. 


\section{Journal of LABORATORY MEDICINE and QUALITY ASSURANCE \\ Yong-Wha Lee et al • STRATUS CS200 for Cardiac Markers}

\section{REFERENCES}

1. Clinical and Laboratory Standards Institute. Evaluation of pecision of quantitative measurement procedures: EP05-A3. 3rd ed. Wayne (PA): Clinical and Laboratory Standards Institute, 2014.

2. Clinical and Laboratory Standards Institute. Evaluation of the linearity of quantitative measurement procedures: a statistical approach: EP06-A. Wayne (PA): Clinical and Laboratory Standards Institute, 2003.

3. Clinical and Laboratory Standards Institute. Measurement procedure comparison and bias estimation using patient samples: EP09-A3. 3rd ed. Wayne (PA): Clinical and Laboratory Standards Institute, 2013.

\section{STRATUS CS200을 이용한 심표지자검사의 성능 평가 이용화 • 김정권 \\ 순천향대학교 의과대학 순천향대학교부천병원 진단검사의학과}

최근 면역측정법 원리가 적용된 현장검사기기로 여러 종류의 심표지자검사를 단 시간 내에 수행 할 수 있는 STRATUS CS200 (Siemens Healthcare Diagnostics Inc., USA)이 개발되었다. Troponin I, creatine kinase-MB (CK-MB), N-terminal pro-brain natriuretic peptide (NT-proBNP)와 myoglobin 등 총 4종목에 대하여 Clinical and Laboratory Standards Institute에 제시된 평가지침에 따라 정밀도, 직선성, 상관성, 정량한계 및 검사소요시간을 평가하였다. 4종목의 총 변이계수는 $1.90 \%-4.25 \%$ 의 값을 보였고, 직선성 평가에서 4종목 모두 제조사 제시범위 내에서 결정계수가 0.99 이상으로 우 수한 직선성을 보였다. 기준장비인 E170 (Roche Diagnostics, Germany)과의 상관성 평가에서 4종 목 모두 밀접한 상관성을 보였다. 제조사에서 제시한 정량한계치는 troponin I, CK-MB, myoglobin 과 NT-proBNP가 각각 $0.03 \mathrm{ng} / \mathrm{mL}, 0.3 \mathrm{ng} / \mathrm{mL}, 1 \mathrm{ng} / \mathrm{mL}$ 와 $15 \mathrm{pg} / \mathrm{mL}$ 였고, 검사소요시간은 한 결 과를 얻기까지는 14분이 소요되었다. STRATUS CS200으로 시행한 심표지자검사는 정밀도, 직선 성, 정량한계 및 검사속도에 있어서 매우 만족할 만한 성능을 보였고, 기존 검사법과도 좋은 상관성 을 보였다.

(J Lab Med Qual Assur 2017;39:181-184)

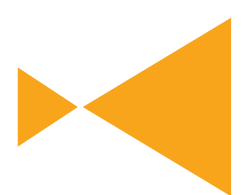

Journal of

LABORATORY MEDICINE and

QUALITY ASSURANCE

교신저자: 이용화

우)14584 경기도 부천시 원미구 조마루로 170 , 순천향대학교 의과대학 순천향대학교부천병원 진단검사의학과

Tel: 032)621-5943, Fax: 032)621-5944, E-mail: lywmd@schmc.ac.kr 